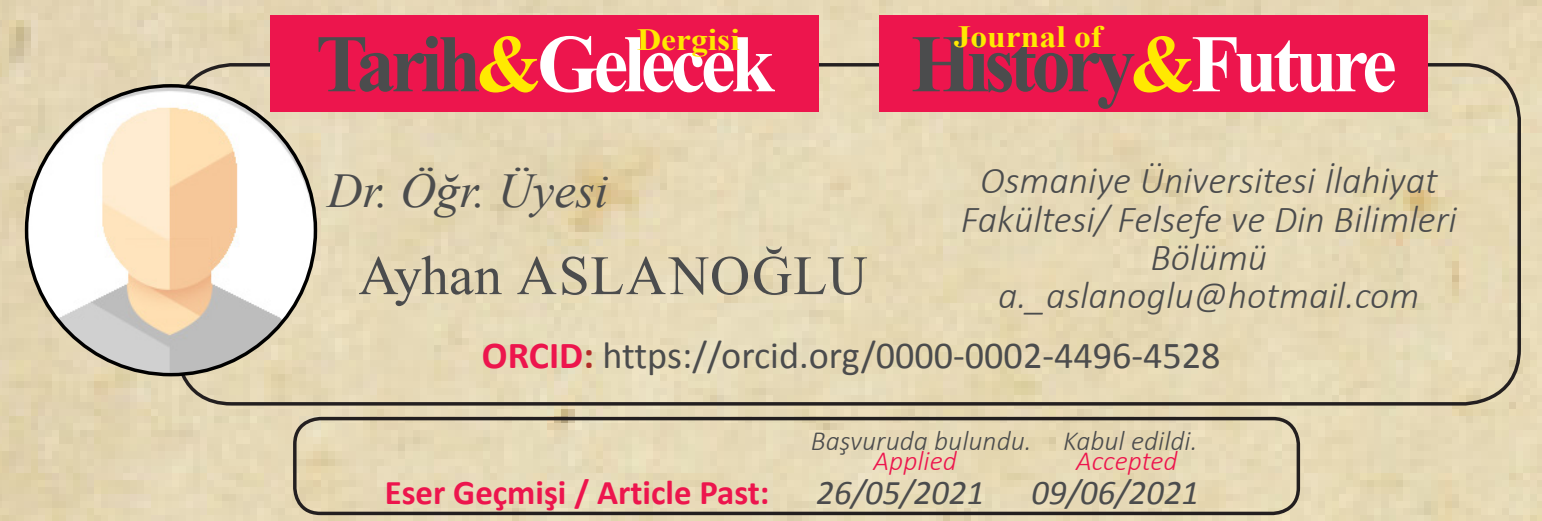

Araştırma Makalesi

DOI: http://dx.doi.org/10.21551/jhf.943388

Research Paper

Indexed by

ERIHPJUNALS

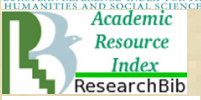

RiSA $\mathbf{M}$

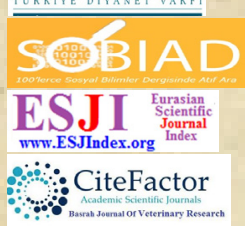

ideal

Orjinal Makale / Orginal Paper

\title{
Afrika Kitasında Nilotik Bir Halk: Dinkalar ve Geleneksel Dinka Dini
}

\section{A Nilotic People in the African Continent: Dinkas and Traditional Dinka Religion}

\section{$\ddot{O} z$}

Dinkalar, Güney Sudan'da yaşayan Nilotik halklardan biridir. Yarı göçebe klanlar şeklinde yaşayan Dinkalar, kendine özgü gelenekleri ile bilinmektedir. Dinka toplumunda sığır yetiştiriciliği sosyal, ekonomik ve dini hayatın ayrılmaz bir parçasıdır. Öyle ki doğumdan ölüme kadar hayatın her safhasında yer alan sığır yetiştiriciliği, Dinka klanlarını direk veya dolaylı olarak etkilemektedir. Tarihi süreçte Dinka toplumu içerisinde, Hıristiyanlık ve İslam dinini kısmen kabul edenler olsa bile, çoğunluk Geleneksel Dinka dinini devam ettirmiştir. Geleneksel Dinka dininde akla ilk gelen insanüstü varlıklar Nhialik ve Jok'tur. Nhialik aynı zamanda yaşamın kaynağı ve yaratıcısı olarak da görülür. Dinka dininde tanrısal varlıkların yanı sıra, atalar ve tabiat kuvvetlerine inanma da önemli bir rol oynamaktadır. Klanlar arasında tanrılar, atalar ve tabiat ruhları için kurbanlar kesilmektedir. Bu etnik grupta doğum, erginlenme, evlilik ve ölüm ile ilgili inanış ve uygulamalarda önem arz etmektedir. $\mathrm{Bu}$ araştırmanın temel gayesi Afrika kıtasındaki Nilotik halklardan biri olan Dinkalar ve geleneksel dinlerini mevcut kaynaklar ışı̆ı̆ında bilimsel olarak ele almaktır.

Anahtar Kelimeler: Dinkalar, Geleneksel Dinka Dini, Güney Sudan, Dini Pratikler.

\section{Abstract}

Dinkas are one of the Nilotic people living in South Sudan. Living in the form of semi-nomadic clans, the Dinkas are known for their unique traditions. Cattle breeding is an integral part of social, economic and religious life in Dinka society. So much so that cattle breeding, which takes place in every stage of life from birth to death, directly or indirectly affects the Dinka clans. In the historical process, the majority of the Dinka society continued the Traditional Dinka religion, even if there were 
those who partially accepted the religion of Christianity and Islam. The first superhuman beings that come to mind in the traditional Dinka religion are Nhialic and Jok. Nhialic is also seen as the source and creator of life. In Dinka religion, belief in ancestors and natural forces plays an important role as well as divine beings. Among the clans, sacrifices are made for gods, ancestors and nature spirits. Beliefs and practices related to birth, initiation, marriage and death are important in this ethnic group. The main purpose of this research is; The aim is to scientifically discuss the Dinka, one of the Nilotic peoples in the African continent, and their traditional religions in the light of available sources.

Keywords: Dinkas, Traditional Dinka Religion, South Sudan, Religious Practices.

\section{Giriş}

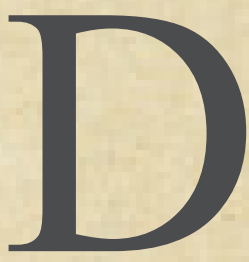

inkalar, Afrika kıtasında Güney Sudan'ın Nil havzası yataklarında $6^{\circ}$ ile $10^{\circ}$ enlem ile $26^{\circ}$ ile $32^{\circ}$ boylamları arasında yaşayan Nilotik halklardandır. $\mathrm{Bu}$ topluluğun beş yüz bin ila iki milyon arasında değișen nüfusunun olduğu tahmin edilmektedir. Dinkalar haricinde bu bölgede Anuak, Nuer, Atuot ve Shilluk Nilotik halkları da bulunmaktadır. Dinka toplumu arasında Dinka dili konuşulmaktadır. Dinka dili Güney Sudan'daki Nuer topluluğunun dili ile de yakından ilişkilidir. Dinka dili; Bor, Agar, Ruweng, Padang, Rek gibi beş ana bölgesel lehçeye sahip olmakla birlikte kendi içerisinde de lehçelere ayrılabilmektedir. ${ }^{1}$

Dinkalar kendilerini "Monyjien veya Jien" olarak adlandırmaktadır. "Halkın İnsanları" anlamında kullanılan bu sözcüklerin Dinka dilindeki en güçlü kavramlardan biri olduğu belirtilmektedir. Aynı zamanda bu kavramlar Dinkaların üstünlüklerini de yansıtmaktadır. $\mathrm{Bu}$ ifadelerin yanı sıra uzun boylu olmalarından dolayı "The Men of Men" (Erkeklerin Erkekleri) anlamında terimlerde kullanılmaktadır. ${ }^{2}$

Dinka topluluğu genel olarak klanlar şeklinde yaşamlarını sürdürmektedir. Güney Sudan bölgesinde birçok Dinka klanı yaşamaktadır. Dinka klanları kendi içerisinde ikiye ayrılmaktadır. Bunlardan birincisi "kic", sıradan kimse ve savaş̧̧ klanlar, ikincisi de sembolleri "sacred fishing spear" (kutsal balıkçılık mızrağı) olan bany veya rahipler olarak ifade edilmektedir. ${ }^{3}$ Klanlar halinde yaşayan bu toplum, son dönemlerde yanı başlarında yaşayan Nuer ${ }^{4}$ toplumu ile sık sık sığır

1 Francis Mading Deng, The Dinka of the Sudan (IIIinois: Waveland Press, 1972), 187; J. W. Burton, "Dinka", Worldmark Encyclopedia of Cultures and Daily Life, ed. Timothy L. Gall ve Jeneen Hobby (Printed in the United States of America: Gale-Cengage Learning, 2009), 158; Alex Kamwaria ve Michael Katola, "The Role of African Traditional Religion, Culture and World-View in the Context of Post- War Healing among the Dinka Community of Southern Sudan", International Journal of Humanities and Social Science 2, sy 21 (2012): 50; Jamie Stokes, "Dinka", Encyclopedia of the Peoples of Africa and Middle East, ed. Anthony Gorman ve Andrew Newman (New York: Infobase Publishing, 2009), 174.

2 Kamwaria ve Katola, "The Role of African Traditional Religion, Culture and World-View in the Context of Post- War Healing among the Dinka Community of Southern Sudan", 50.

3 Godfrey Lienhardt, Divinity and Experience: The Religion of the Dinka (Oxford: Clarendon Press, 1961), 8 .

4 Nuer'ler, Sobat ve Bahr el Ghazal’ın birleştiği bölgenin güneyindeki bataklık ve savanlar da yaşamaktadırlar. Özellikle kültürel olarak Dinkalara benzemektedirler. E.E. Evans ve Pritchard, The Nuer (Oxford: Clarendon Press, 1946), 3. 
hırsızlıkları ve sığırları otlatma yeri konusunda çatışmalara maruz kalmıştır. Bu çatışmalar, her defasında birçok insanın ölümü ile sonuçlanmıştır. ${ }^{5}$

Geleneksel Afrika dinleri içerisinde yer alan Dinkaların tarihçesi, dini inançları, geçiş dönemleri ve dini pratikleri çeşitli açılardan ele alınarak bilim dünyasına katkı sağlanması amaçlanmıştır. Bu bakış açısı ile Dinka toplumunun ele alınıp incelenmesi bölgede yaşayan diğer Nilotik halklar hakkında da bilgi sahibi olunması açısından önem arz etmektedir.

\section{Dinkaların Tarihçesi}

Dinkaların yaşadığı Güney Sudan bölgesi Sudd adıyla bilinmektedir. Bu bölgede tarih öncesinde Nilotik halkların atalarının yaşadığı ve M.Ö. 3000 yıllarından itibaren sığır besleyen, tarımla uğraşan bir halk oldukları belirtilmektedir. Bu Nilotik halkın, M. S. 1500'ler de bölgede hakim unsur olarak ortaya çıktığı ve 17. yüzyıla kadar Nil havzasındaki bataklıklarda sürekli topraklarını genişletme yoluna gittiği ifade edilmektedir. ${ }^{6}$

Dinkalar, Yunan ve Misırlı gezginler ve coğrafyacılar tarafından binlerce yıl önce fark edilmiştir. ${ }^{7}$ Sudan'ın batısında yer alan Darfur bölgesine 7. yüzyılda Nil Nehri ve Büyük Sahra güzergahından farklı kabilelerin geldiği belirtilmektedir. Dacuların o tarihlerde ilk kurulan kabile devleti olduğu ve uzun bir süre bölgede hakimiyetini devam ettirdiği bilinmektedir. Müslüman coğrafyacılar, 8. yüzyıl itibariyle, Doğu Afrika'nın sınırları içerisinde yer alan Sudan'ın da içerisinde olduğu bölgeye Biladüssudan ismini vermişlerdir. Orta ve Doğu Sudan'ın yer aldığı bölgeye son yüzyıllarda Fransız Sudan'1, bugünkü Sudan topraklarının bulunduğu yere de İngilizMisır Sudan'1 denilmiştir. Sudan Devletinin sınırları 19. yüzyılda Mısır Hidivliği döneminde son şeklini almıştır. ${ }^{8}$ Bölge uzun bir süre farklı uluslar tarafından yönetilmiştir. İngilizlerin ayrılması ile Sudan Devleti, 1956 yılında bağımsızlığını ilan etmiştir. ${ }^{9}$

19. yüzyılda Sudan devletinin kuzeyinin Osmanlı İmparatorluğu hakimiyetinde olduğu, güney bölümüne ise Dinkaların direnişinden dolayı Osmanlıların pek nüfuz edemediği görülmektedir. Sudan'ın kuzey bölgelerinde İslam dininin kabul edilmesine rağmen güneyde yaşayan Dinka toplumu İslamiyet'i kabul etmemiştir. İngilizler güneyde yaşayan Dinkaları büyük ölçüde kontrol altına almak için çok çaba sarf etmiştir. Dinkaların yaşadığı bölgede Arap kültürünün ve siyasetinin baskısı, sömürgecilik girişimleri gibi nedenler çoğu kez çatışmalara yol açmıştır. Sudan hükümeti, 1983 yılında Dinka toplumunun gücünü kırmak için Sudan'ın güneyini üç bölgeye ayırmıştır. Aynı yıl Sudan Devleti'nin şeriat yasasını kabul etmesi ile Güney Sudan bölgesinde yer alan grupların isyan etmesine ve iç savaşın patlak vermesine sebep olmuştur. Güneydeki birçok isyancı grup Dinkalar tarafından desteklenmiştir. Dinka köylerine 1988 yılında yapılan karşı saldırılar sonucu büyük katliamların gerçekleştirildiği bilinmektedir. Hartum'da yirmi yıl süren, kuzeygüney savaşlarından sonra 2005 yılında Hartum' daki hükümet ile isyancılar arasında antlaşmaya

5 http://merkezstrateji.com/assets/media/140124-varlik-gueney-sudandaki-gelismeler.pdf..(Erişim 29/04/2021)

6 Stokes, "Dinka", 174.

7 Burton, "Dinka", 158.

8 Ahmet Kavas, "Sudan", Türkiye Diyanet Vakfi İslam Ansiklopedisi (İstanbul: Türkiye Diyanet Vakfı Yayınları, 2009), 459-60.

9 Deng, The Dinka of the Sudan, 138. 
varılmıştır. Bu savaşlar sırasında birçok Dinkalı, Sudan'ı terk etmek zorunda kalmıştır. ${ }^{10}$ Dinkaların yaşadığı Güney Sudan Devleti, 2011 yılında bağımsızlığını ilan etmiştir. Bağımsızlık sonrası bölgede yer yer çatışmalar devam etmiştir. ${ }^{11}$

\section{Geleneksel Dinka Dini}

Tarihsel süreç içerisinde Dinka toplumunda Hıristiyanlık ve İslam dinini benimsemiş olan gruplar yer almıştır. Buna rağmen Geleneksel Dinka dini bariz bir şekilde varlığını devam ettirmiştir. ${ }^{12}$

\subsection{Tanrı Anlayış̧ları}

Geleneksel Dinka dininde bir birtakım yath'lere (yeeth: çoğul hali) inanılmaktadır. Bu yath'ler "Tanrılar ve Güçler" anlamında kullanılır. Bu tanrıları ve insanüstü güçleri belli bir şekilde ifade etmek her zaman mümkün olmamaktadır. Bununla birlikte yath'ler şu şekilde ifade edilmektedir.

- Gökyüzünde baba veya yaratıcı olarak kabul edilen insanüstü varlık (Nhialik)

- Yağmur ${ }^{13}$, gök gürültüsü, şimşsek ile ilişkilendirilen Deng

- Güneş ile ilişkilendirilen Garang (İlk Erkek)

- Nehirlerle özdeşleştirilen Abuk (Illk Kadın)

- Ölüm ve kısırlığın kaynağı olan Macardit

Diğer yath'ler klanların simgeleri içerisinde kalmaktadır. Dinka klanları ve grupları birbirleri ile temasa geçtikçe yeni yath'ler kabul etmişlerdir. ${ }^{14}$

Geleneksel Dinka toplumunda "Dinka dini" ifadesine birebir karşlık gelen herhangi bir ifade yoktur. "Din" sözcügü sadece tanrıyı değil, aynı zamanda atalara ve tabiat güçlerine de atıfta bulunur. Dinkalar, Nhialik (yüksekte, gökte olan ${ }^{15}$ ) adını verdikleri tanrıyı, ruhunun en yüksek tezahürü olarak kabul eder. ${ }^{16}$ Nhialik, Dinka halkının gökyüzü ruhu olarak tanınır. Diğer düşük ruhlar ise dua, ibadet ve kurban şeklindeki ritüellerle Dinka halkı tarafından kabul görür. Nhialik her şeye gücü yeten, yaratıcı ve ulaşılması zor bir gökyüzü ruhu olarak kabul edilir. Yağmur, şimşek, gök gürülttüsü Nhialik'in gökten inen tezahürleri olarak bilinir. Yağmurlu havalarda güneş ortaya çıkarken oluşan gökkuşağının ise Nhialik' in gerdanlığı olduğuna inanılır. ${ }^{17}$ Bununla birlikte Padang Dinka topluluğuna göre Nhialik, aynı zamanda Acek tanrısıdır. Bu iki kavram cennette yaşayan tek tanrının iki ismi olarak kabul edilir. ${ }^{18}$

\footnotetext{
10 Stokes, "Dinka", 174-75.

11 http://merkezstrateji.com/assets/media/140124-varlik-gueney-sudandaki-gelismeler.pdf..(Erişim 29/04/2021)

12 Stokes, "Dinka", 176.

13 Bkz. E.E. Evans- Pritchard, Nuer Religion (Oxford: Clarendon Press, 1956), 29.

14 Stokes, "Dinka", 176.

15 Arthur Nebel, "Dinka-English, English-Dinka Dictionary” (Bologna: E.M.I, 1979), 65,145.

16 Kamwaria and Katola, "The Role of African Traditional Religion, Culture and World-View in the Context of Post- War Healing among the Dinka Community of Southern Sudan", 51.

17 Douglas Thomas- Temilola Alanamu (ed.), African Religions: Beliefs and Pratices through History, 251.

18 Ibrahim Bedri, "More Notes on the Padang Dinka", Sudan Notes and Records 29, sy 1 (1948): 42.
} 
Yüce Varlık olan Nhialik, aynı zamanda bereket ve yağmur tanrısı olan Deng ile de ilişkilendirilir. Hatta bazı bölgelerde Nhialik' in bilinmediği, onun yerine Deng'in yüce varlık olarak kabul edildiği görülmektedir. Yine bu iki insanüstü varlığın bazı bölgelerde de aynı ruh ${ }^{19}$ olduğu belirtilmektedir. ${ }^{20}$ Dinkalar tanrının tüm insanları yaratan ve yok eden bir varlık olduğuna inanır. Aynı zamanda Dinkalar kendileri dışındaki insanların farklı dinlere ve tanrılara inandıklarını da ekseriyetle kabul etmektedir. ${ }^{21}$ Dinka klanlarında söylenen bir tür ilahiye göre tanrı, "yaratıcı ve baba” olarak ön plana çıkmaktadır. Bunun en büyük göstergesi aşağıdaki şekildedir:

Beyaz olana dua ederim

Tanrı yakın değil mi?

Babam bize hayat vermiyor mu?

Abuk'un oğlu Deng, yaşam için dua mı ediyor.

Yukarıdaki ifadelere göre, Dinkalar kendilerinin huzur içinde olmasını istediklerinde bir yaratıcı ve baba olarak tanrıya bu şekilde seslenmektedir ve bir sorunla karşılaştıklarında, tanrıdan kendilerinin yanında olmasını istemektedir. ${ }^{22}$

Dinka toplumunda insanüstü varlıklar için kullanılan başka bir sözcükte Jak’tır. Bu sözcüğün tekil kullanımı ise J'ok'tur. (ruh, iyi ve kötü ruh) ${ }^{23}$ Jok kelimesi Uganda ve Kongo'daki bazı etnik gruplar tarafından da kutsiyet atfedilip kullanılır. Bu toplumlarda da yüce tanrı (yaratıcı ruh) olarak görülen Jok, her yerde ve her şeydedir, anlayışı benimsenmektedir. Jok, dünya üzerinde yaşayan hayvanları ve insanları yaratan, onlara hayat verendir. ${ }^{24}$

Padang Dinkaları arasındaki bazı klanlar Jok'u Acek'in emri ile hareket eden bir melek ve yer ile cennet arasında yaşayan bir varlık olarak görür. Jok ile ilgili bir inanışa göre bir kişi hastalandığında Nhialik'e kurban teklif eder. Nhialik bu teklifi kabul edince Jok'a iyileşme sözü gönderir ve hastalanan kişi iyileşir. Bu hastalığın iyileşmesine aslında Nhialik neden olmuş olur. Fakat Nhialik iyileştirmeyi reddedip kişi öldüğünde ise bu durumun Jok’tan kaynaklandığı söylenir. Padang Dinka klanları arasında Acek ve Nhialik yaratılışı, Jok ise yok oluşu temsil eder. ${ }^{25}$

Dinkalar arasında "Ölümün Kökeni” adı verilen bir efsaneye göre, Jok insanlara ölümsüz olabilmeleri için hayat ağacının meyvesini vermeyi vadetmiştir. Jok, bu hediyeyi vermek için insanları cennete çağırdığında onlar cennete gelmeyi geciktirmişlerdir. Bunun üzerine Yüce Yaratıcı, hayat ağacının meyvelerini aya, güneşe ve yıldızlara vermiştir. Daha sonra meyveyi almaya gelen insanlara hiç meyve kalmadığı için insanlar ölümsüz olamamıştır. ${ }^{26}$

19 Lienhardt, Divinity and Experience: The Religion of the Dinka, 94.

20 Katherine Olukemi Bankole, “Creation”, Encyclopedia of African Religion, ed. Molefi Kete Asante- Ama Mazama (California: Sage Publication, 2009), 185; Kamwaria- Katola, "The Role of African Traditional Religion, Culture and World-View in the Context of Post- War Healing among the Dinka Community of Southern Sudan", 51.

21 Deng, The Dinka of the Sudan, 126.

22 Lienhardt, Divinity and Experience: The Religion of the Dinka, 38-39.

23 Nebel, "Dinka-English, English-Dinka Dictionary", 36.

24 Patricia Ann Lynch, “Jok”, African Mythology A to Z (New York: Fact on File, 2004), 53.

25 Bedri, "More Notes on the Padang Dinka", 42-43.

26 Lynch, “Jok”, 54. 
Dinka toplumunda gök tanrıları veya özgür tanrılar adı ile anılan tanrılar panteonu, klanlardaki küçük tanrılardan ve atalara bağlı klan tanrılarından ayrılır. ${ }^{27}$ Dinka inanç sisteminde öne çıkan özgür tanrılardan biri de Garang’tır. Garang'ın farklı çağrışımları ve sembolik renkleri vardır. Yer ve gökyüzünün ayrılması mitinde kendisinden bahsedilen ve ilk insana verilen isim olarak betimlenmektedir. Garang genelde erkeklerle ilişkilendirilir. Garang'ın bazı insanların bedenlerinin içerisine yukarıdan girdiği ve bu şekilde gökyüzünün gücünün o bedenlerin içerisinde olduğuna inanılır. Bu erkeklere "Garang Erkekleri” adı verilir. Garang erkekleri Batı Dinka ülkesinde oldukça fazladır. Bu erkeklerin parmakları yüzüklerle, bilekleri bilekliklerle kaplıdır. Birer şifacı olarak görülen Garang erkekleri çocuklarını iyileştirmek isteyen annelerin hediyeleri ile donatılır. Garang erkeklerinin hastalıkları iyileştirme konusunda büyük başarı gösterdiklerine inanılır. ${ }^{28}$

Güney Sudan'da yaşayan Nuer ve Dinka halkının inanç sisteminde yer alan başka bir figür ise ilk kadın Abuk'tur. Aynı zamanda Abuk için "Buk, Abek" kavramları da kullanılır. Abuk arketip bir kadın ve anne olarak kabul edilir. Kadınların mesleklerine başkanlık yapar. Dinkalar arasında bazen tanrısallık ile ilk kadının aynı olduğu bazen de Abuk'un Deng'in annesi olduğu ve Garang'ın karısı olduğu söylenir. Abuk'un kim olduğuna dair görüşler çeşitlilik arz etse bile onun hakkında bilinen en önemli ve kesin özellik onun kadınlarla çeşitli açılardan bağlantı içerisinde olmasıdır. Mitolojik bir anlatıya göre, Abuk çok küçük olarak doğmuştur. Daha sonra normal bir boyuta ulaşmıştır. Onun ilk arkadaşı kutsiyet atfedilen Garang'dır. Onların yaşadıkları dönemde cennet ve dünya birbirine bir iple bağlanmıştı. Nhialik, Abuk ve arkadaşına yemeleri için her gün bir tahıl tanesi vermiştir. Bu tahıl tanesi ile doymayan Abuk, gökteki Nhialik’ten tahıl çalmış ve onları yeryüzündeki topraklara dikmiştir. Tahılların hasat zamanında onları biçerken çapası Nhialik'e çarpmış ve Nhialik Abuk'un yaptığı bu saygısızlığa karşı yeryüzü ile cennet arasındaki ipi koparmıştır. Abuk ile ilgili başka bir efsaneye göre, yağmur tanrısı Deng ile evlendiği ve iki kızının olduğu ifade edilir. Dinkalar arasında Abuk hakkında anlatılan bu olağanüstü hikayeler onun insan statüsünden tanrısal bir varlığa dönüşmesinde etkili olmuştur. Bu çerçevede Abuk’un tarımsal faaliyetlerin, doğurganlığın ve nehrin tanrıçası olduğu, sembollerinin ise yılan, koyun ve ay olduğuna inanılır. ${ }^{29}$

Dinka toplumu içerisinde başka bir insanüstü varlık ise Macardit'tir. Dinkaların büyük bir kısmı tarafından Macardit ve Colwic'in tanrısallığının aynı olduğu düşünülür. Rek Dinka topluluğu, tarafından Colwic kavramı pek kullanılmaz. Macardit'in kadınlarla ilişkili olduğuna inanılır. Özellikle doğurganlığı sona erdirmesi ile bilinir. ${ }^{30}$ Dinka toplumunda gebe kadınların doğum yapıp çocuk dünyaya getirmesi, sığırların çoğalıp halkın geçiminin temin edilmesi önemli görülür. $\mathrm{Bu}$ yüzden Macardit'in bu tür kısıtlamalarda bulunması Dinkalar açısından olumsuz sonuçlar doğurmaktadır.

Gökyüzü ruhlarına karşılık aşağıdakilerin (yeryüzü) ruhlarının insanlara daha yakın olduğuna inanılır. Bu ruhlar bireylere bağlı totemistik ruhlar, doğa ruhları ve diğerleri şeklinde yerel gruplara bağlı totemik ruhlar olarak da ayrılır. Așağıdaki ruhlar gökte ki ruhlardan daha

27 John Middleton, "Nuer and Dinka Religion", Encyclopedia of Religion, ed. Lindsay Jones (Detroit: Macmillan Reference USA, 2005), 6744.

28 Lienhardt, Divinity and Experience: The Religion of the Dinka, 81-85.

29 Douglas Thomas- Temilola Alanamu (ed.), African Religions: Beliefs and Pratices through History, 4344; Lienhardt, Divinity and Experience: The Religion of the Dinka, 89-90.

30 Lienhardt, Divinity and Experience: The Religion of the Dinka, 81-83. 
önemsiz görüldüklerinden çok saygı görmemektedir. ${ }^{31}$

\subsection{Atalar ve Tabiat Kültü}

Geleneksel Afrika dinlerinde atalar kültünün önemi büyüktür. Atalar kültünün birtakım psişik güçlere sahip olduğu kabul edilir. ${ }^{32}$ Dinka toplumunda atalara saygı duyulur ve ataların ölümden sonrada yaşamlarının devam ettiğine inanılır. Bu inanışın temelinde ölüler ile iletişim kurulduğu düşüncesi hakimdir. Dinkalar ölen akrabalarının ruhlarını, canlı ve ilahi varlıklar arasında aracı olarak görürler. Aynı zamanda atalarının kendileri için şifacı olduğuna ve onların özel güçleri sayesinde kendilerine yardım ettiğine inanırlar. Dinkalar atalarının ruhlarını kuşlar ve farklı yılan şekillerinde somutlaştırma yoluna gitmişler ve doğumdan ölüme kadar birçok ritüelde onları memnun etme gayreti içerisinde olmuşlardır. ${ }^{33}$ Diğer taraftan Dinka toplumunda bir insan öldüğünde ruhun bedeninden ayrılarak atalarının ruhuna gittiğine inanılır. Kurban edilen öküzlerin ruhlarının, atalarının yaşadığı dünyaya gittiği düşünülür. ${ }^{34}$ Ayrıca, bazı hayvanlar inanç, ibadet ve ekonomik anlamda önem teşkil etmektedir. Bu çerçeveden bakıldığında sığırlar ön plandadır. Mitolojik bir anlatıya göre tanrı, insanlara sığırlar ile silahlar arasında bir seçim yapmalarını istemiştir. Dinkaların sı̆̆ırı seçtiği belirtilmektedir. ${ }^{35}$

Dinka toplumunda atalar kültü ile bağlantılı kavramlardan biri de kötülük düşüncesidir. Dinkalar arasında kötülük, "Nuer ve sosyal kirlilik" kavramları ile ifade edilmektedir. Onlara göre kötülük düşüncesi, iç savaş esnasında öldürülenlerin dini inanışlarına göre gömülmemesi ve onların öfkeli ruhlarıdır. Dinka toplumundaki bilge kişiler, savaşlardaki savaşçıların ruhlarının kirlendiklerini ve bu savaşçıların evlerine döndüklerinde toplumun sağlığı için zararlı olduklarını ittifakla kabul eder. Özellikle savaşçıların öldürdükleri kişilerin ruhlarının onlara ve aile üyelerine musallat olduğu düşünülür. Böylece öfkeli ruhların yaşam boyu onların peşini bırakmayacaklarına inanılır. Bu tür savaşçıların eski hallerine dönebilmeleri için tedavi olmaları gerektiği belirtilir. Ölen kişilerin ruhlarını sakinleştirmek ve bir savaşçıyı eski haline döndürmek için temizlenme ritüelleri yapılır. Bu ritüeller sonucunda fiziksel dünya ile manevi dünya arasındaki bağın güçlendiğine inanilır. ${ }^{36}$

Dinka dininde tanrısal varlıklar ve atalar kültünün yanı sıra tabiat kültü de önemli bir unsurdur. Afrika topluluklarında önemli görülen manevi güçlerin insan haricinde tabiat kuvvetlerinde de bulunduğuna inanılır. Bu açıdan bakıldığında tabiat olayları kutsalın bir tezahürü olarak da görülür. Tabiat kültü içerisinde yer alan güneş, ay, gök, su, toprak, hayvan, ağaç birçok dinde ve kültürlerde farklı şekillerde sembolleşmiştir. Onlara karşı gösterilen saygı ve hürmet, icra edilen ritüeller de her daim kendini gösterir. ${ }^{37}$ Dinka toplumunda Yüce Varlık olarak görülen Deng sözcüğü "yağmur”

31 Middleton, "Nuer and Dinka Religion", 6744.

32 Hammet Arslan, "Afrika Topluluklarında Atalar Kültünün Önemi ve İşlevi”, Bartın Üniversitesi İslami Ilimler Fakültesi Dergisi 3, sy 6 (2016): 11.

33 Kamwaria and Katola, "The Role of African Traditional Religion, Culture and World-View in the Context of Post- War Healing among the Dinka Community of Southern Sudan", 51.

34 Douglas Thomas- Temilola Alanamu (ed.), African Religions: Beliefs and Pratices through History, 251.

35 Evans- Pritchard, Nuer Religion, 11.

36 Kamwaria- Katola, "The Role of African Traditional Religion, Culture and World-View in the Context of Post- War Healing among the Dinka Community of Southern Sudan”, 52-53.

37 Hammet Arslan, “Afrika Topluluklarında Tabiat Kültü ve Tabii Unsurlara Atfedilen Güçler”, Bartın Üniversitesi Íslami İlimler Fakültesi Dergisi 4, sy 8 (2017): 2-3. 
anlamına gelmektedir. Afrika kıtasında yağmur yaşamın devamı için çok önemli görülür. Bir efsaneye göre gökyüzünde ansızın hamile bir kadının ortaya çıktığı ve onun gelişinin onuruna insanların ona bir ev inşa ettiği söylenir. Hamile kadın, erkek bir çocuk doğurduğunda kanlı gözyaşları sel olup akar. Bu esnada aşırı bir yağmur yağar ve oğluna Deng adını verir. Kadın, olağanüstü bir şekilde doğan oğlunun halka lider olacağını iddia eder. Nihayet bir süre sonra Deng, halka lider olur ve onları uzun bir süre yönetir. ${ }^{38}$

\subsection{Evrenin Yaratılışı}

Evrenin ve ilk insanın yaratılışı ile ilgili bazı toplumlar da olduğu gibi Dinkalar arasında da mitolojik öyküler anlatılmaktadır. Bu efsanelerden birine göre başlangıçta yeryüzü ve gökyüzü birbiri ile bitişikti. Gökyüzü dünyanın üzerine uzanıyordu. Birbirine bağlanmış olan gökyüzü ve yeryüzü arasında bir halat vardı. İnsanlar bu halat sayesinde istedikleri gibi tanrıya ulaşabiliyordu. O zamanlarda ölüm yoktu. Tanrı, ilk erkek ve ilk kadına ihtiyaçlarını karşılamak için günde bir tahıl tanesi verirdi. Evrenin yaratılışı ile ilgili başka bir efsaneye göre ise başlangıçta dünya zaten yaratılmıştı. Fakat dünyada ışık yoktu ve ışık olmadığı için hiçbir yer görünmüyordu. Bu karanlık içerisinde tanrı insanları yarattı. Bu yarattığı insanlardan birinin adı da Aruu idi. Tanrı onun karanlıkta olduğunu görebilmesi için ona gözler verdi. Tanrı, ona nasıl bir hediyeden hoşlanacağını sordu. Aruu ise "Babam (Tanrım), görmek için küçük bir delik varsa, bende bunu isterdim." diye cevap verdi. Tanrı bu isteğini reddetti. Bu isteğinin yerine bir mızrak ve bir balta teklif etti. Aruu baltayı aldı ve toprağa vurdu. Neden yanmıyorsun? dedi. Bu esnada bir aşağı, bir yukarı doğru gitti. Böylece dünya aydınlandı. Tanrı, Aruu'ya "Bunu neden yapıyorsun? Sana daha önce küçük bir şey verdim ve bunu neden şimdi yaptın? Şimdi sen tutsaksın.", dedi. Bu gelişmelerden sonra tanrı, Aruu'yu yeryüzüne itti ve yeryüzünü gökyüzüne kapatt1. ${ }^{39}$

\subsection{Dini Pratikler}

Dinka toplumundaki dini pratikler, ruh dünyası ile fiziksel dünyanın kesişmesine ve tüm sosyal etkinliklere rehberlik eder. Erkekler belli bir yaşa geldiklerinde erkeklik, kızlar ise kadınlık eğitiminden geçer. $\mathrm{Bu}$ dini pratiklerin yanı sıra Nhialik'e, atalara ve diğer ruhlara dua edilir. Duaların bu tanrılar üzerinde etkili olduğu düşünülür. Tanrıları ve ruhları yatıştırmak için hayvan kurban edilir. ${ }^{40}$ Kurban, "Tanrı ya da bir ilaha sunulan takdime, özellikle de bir ayinde boğazlanarak sunulan bir hayvan; bu yolla takdim edilen herhangi bir şey" olarak tanımlanmaktadır. Kurban ibadeti, geleneksel Afrika dinlerinde önemli bir ibadet unsuru olarak karşımıza çıkmaktadır. ${ }^{41} \mathrm{Bu}$ ibadet şekli tüm dini geleneklerde olduğu gibi Dinka toplumunda da önemli bir yer teşkil etmektedir.

Mızrak ustaları (klan lideri, ruhani şef), mistik güçler ve ritüeller yardımı ile Dinka topluluğunun devamı için olumlu yönde katkı sağlamaktadır. Onların gücü, otoritelerinden çok ikna ve itibara dayanır. Günümüzde mızrak ustalarının etkileri zayıflamış olsa da inanış ve uygulamadaki rolleri hala devam etmektedir. Dinka klanlarının her biri bir bitki veya hayvan

38 Lynch, "Jok", $29,95$.

39 Lienhardt, Divinity and Experience: The Religion of the Dinka, 33-35.

40 Douglas Thomas- Temilola Alanamu (ed.), African Religions: Beliefs and Pratices through History (Santa Barbara: ABC-CLIO, 2019), 179.

41 S. A. Adewale, “Afrika'nın Geleneksel Dininde Kurban”, çev. Ahmet Güç, Uludağ Üniversitesi İlahiyat Fakültesi Dergisi 7, sy 7 (1998): 587. 
ile ilişkilidir. Klan üyeleri, klan fetişlerine zarar vermez ve onlara saygı duyar. ${ }^{42}$ Mızrak ustası klanlarının ibadet yerleri (tapınakları) küçük çamur yığınlarından meydana gelmektedir. Aynı zamanda bu tür küçük tapınaklar savaşçı klanların önemli olanlarının evlerinde de bulunur. Rahip klanının ilki kabul edilen Aiwel Longar'a ait olduğu düşünülen höyük kalıntılarının Bahar el Zeraf bölgesinde olduğu belirtilmektedir. ${ }^{43}$ Tapınaklar ve kutsal mızraklar Aiwel Longar'a atfedilir. Efsaneye göre, bir adam ve bir aslan dans eder. Bu esnada aslan, adamın kolundaki bilekliği ister. Buna karşın adam bilekliğini vermeyi reddeder. Aslan, adamın baş parmağını ısırır ve adam ölür. Adamın hiç oğlu yoktur. Bunun üzerine kadın nehre gider, eşi için ağlamaya başlar. Kadın ağlarken nehrin ruhu kadına seslenir. O ruh kadına, eteğini kaldırmasını ve suların rahminden içeri akmasına izin vermesini ister. Böylece kadının bir oğlu olur. Bu erkek çocuk daha sonraları Aiwel Longar ismi ile çağrılır. Olağanüstü bir şekilde doğması ve çoğu olumsuzlukların üstesinden gelmesi onun halk tarafindan kutsal bir kişi olarak görülmesine sebep olmuştur. Dinka sözlü geleneğinde Aiwel Longar, Dinka halkının ortak atası olarak görülür. ${ }^{44}$

Geleneksel Dinka dininde göze çarpan dini pratiklerden biri Erginlenme (Kabul Töreni) törenidir. Erginlenme töreni, Dinka toplumunda erkeğin statüsünü belirleyen önemli bir faktördür. $\mathrm{Bu}$ tören çocuklar yaklaşık on altı- on sekiz yaşlarına geldiklerinde gerçekleştirilir. Bu törene cesaret, şiddet ve saldırganlık gibi kriterler damgasını vurur. Ayrıca kendini sınırlama, dayanıklılık, sorumluluk gibi durumları da ortaya çıkarır. Erginleme töreni yapılana kadar kişi, topluluk önünde çocuktur. Çocuk, bu törene kadar süt sağmanın yanı sıra sığır yetiştiriciliğinin günlük işlerini yapar. Bu etkinliklerin dışında toplu yerlerde şarkı söyleme, dans etme, kızlarla flört etme yasaktır. Erginlenme töreni, Dinka ve Nuer topluluklarında erkek çocuklarının yetişkinliğe geçmesinin bir işareti olarak "yüz nişanı ritüeli” olarak da bilinir. Bu ritüel, ergenlik çağına gelen erkek çocuklarının aile büyükleri toplanıp ortak bir karar vermesi sonucu başlar. Törende yöresel danslar icra edilir. Hayvanlar kurban edilip ziyafetler düzenlenir. Bir tür festival gibi coşku ile kutlanır. Bu ritüelden önce ve sonra erkek çocukları ile ilgili bazı kısıtlamalar getirilir. Yüz nişanı ritüelinde, törene katılan çocukların yüzleri keskin bir bıçakla "v" şeklinde veya "paralel çizgiler" olacak şekilde yedi ile on kadar derin iz bırakılarak kesilir. Ayrıca her kabilenin kendine has sembolleri yüze çizilir. Bu aynı zamanda bir dayanıklılık testi gibi de görülür. Erkek çocuklarının yüz nişanları yapıldıktan sonra törene katılan çocukların evine gidilir ve gece, o evde geçirilir. Gecenin sabahında çocuğun ailesi tarafından bir hayvan kesilir. Yüz nişanı yapılan çocukların hepsinin evine gidilmesi şeklinde ritüel devam eder. Ev ev dolaşma bittikten sonra yaşlı bir kişi bu çocuklara, o andan sonraki hayatları için rehberlik eder. Rehberlikteki amaç, yüz nişanı ritüelinden sonra kabiledeki rollerini öğretmektir. ${ }^{45}$

Dinkalar arasında barış töreni önemli bir uygulamadır. Bu tören iki klan arasında meydana gelen ölümlü kavgalar sonucunda barışmak için yapılır. Barış töreni genelde sığırlar verilerek yapılan bir uygulamadır. Verilecek olan sığırlar ve sayıları Dinka kabileleri arasında farklılık gösterir. Genelde öldüren klan üyesi ölen kişinin ailesine inek, boğa bazen de bir kız verir. Kan

42 Kamwaria- Katola, "The Role of African Traditional Religion, Culture and World-View in the Context of Post- War Healing among the Dinka Community of Southern Sudan", 50; Stokes, "Dinka", 176.

43 Lienhardt, Divinity and Experience: The Religion of the Dinka, 257-63.

44 Douglas Thomas- Temilola Alanamu (ed.), African Religions: Beliefs and Pratices through History (Santa Barbara: ABC-CLIO, 2019), 178-179; Burton, "Dinka", 1/159; Lienhardt, Divinity and Experience: The Religion of the Dinka, 261.

45 Deng, The Dinka of the Sudan, 68-70; https://www.aa.com.tr/tr/dunya/guney-sudanda-yetiskinligin-vegosterisin-ilk-sarti-yuz-nisani/976200\# (Erişim 15/05/2021), t.y. 
parası olarak verilen bu bedeller taraflar arasında yaşanan kan davasını ortadan kaldırmak içindir. Barış töreni öncesi hazırlıklar yapılır. Kan davası için sığır adedi belirlendikten sonra barış töreni başlar. Beny Rem (ruhani şef), suffar ağacından yapılmış bir tokmakla sığırlara dokunarak onları mağdur aileye teslim eder. Indrap ağacı ile de ateş yakılır. Kan parası olarak verilen boğalardan biri kurban edilerek ikiye ayrılır. Her iki parça, iki tarafta ayrı ayrı pişirilir. Her iki taraf, pişirilen etin bir kısmını getirerek birbirine karıştırır ve birlikte yer. Yemek sonrası çubuklarla karşılıklı tütün içilir. Daha sonra öldüren ve ölen kişinin yakınları mızraklarını karşılıklı değiştirir ve heglig ağacına çarpar. Yaptıkları bu ritüelle aralarındaki kan davasının bu ağaca geçtiğine inanılır. Kurban edilen boğanın derisinin parçaları köylerine dönenler tarafından götürülür. $\mathrm{Bu}$ deri parçaları törende bulunamayan kadın ve çocuklar için ateşte yakılır. Ateşte yakılan deriden çıkan dumanlar kadınlar ve çocuklar tarafından koklanır. Dinkalar arasındaki barış töreninde kan parası olarak kız kabul edildiğinde ise öncelikle bedel verilecek kız, bir boğa ve buzağı ile erkeklerin ve akrabalarının ileri gelenlerinin önüne getirilir. Boğa yukarıda anlatıldığı gibi kurban edilir. Kızın beline bir ip dolandırılır. Daha sonra kız, öldürülen kişinin annesi veya yakın akrabası olan bir kadına teslim edilmek için götürülür. Teslim edilmeden önce kızın kıyafeti çıkarılır. Teslim alınan kızın belindeki ip çıkarılır ve bir giysi giydirilir. Oradan nehre götürülüp kızın bacakları ve yüzü yıkanır. Temizlendikten sonra ölen kişinin köyüne götürülür. Köye vardıklarında bir kurban kesilir. Kız, kesilen bu kurbanın üzerinden geçerek köye girer. Bir ay sonra kız bir buzağı ile ebeveynlerinin yanına döner. Belli bir süre sonra öldürülen kişinin varsa erkek kardeşi tarafından kabul edilir. Doğurduğu çocuklarının hepsi öldürülen kişinin çocukları olarak kabul edilir. Dinkalar arasındaki başka dini bir pratikte sağlık merasimidir. Halk arasında öksürük ve sıtma gibi hastalık baş gösterdiğinde Beny Rem veya Mendyor (kutsal kişi, ruhani şef) hastalığı iyileştirmek ve onu uzaklaştırmak için sağlık töreni yapar. Hastalık töreni için küçük bir hayvan ve tereyağı içeren su kabağı törenin yapılacağı yere getirilir. Kurban edilecek hayvan ve su kabağı anneleri tarafından taşınan çocukların başları üzerinden Beny Rem tarafından geçirilir. Daha sonra Beny Rem, kutsal bir ineğin tereyağının bulunduğu başka bir su kabağını getirir. Eli ile içerisinden biraz alıp törende hazır bulunanların göğsüne dokunur. Bu uygulamadan sonra her iki su kabağı nehre atılır. Böylece hastalığın uzaklaştırıldığına inanılır. ${ }^{46}$

Dinka toplumunda sığır yetiştiriciliği sosyal, ekonomik ve dini hayatın ayrılmaz bir parçasıdır. Öyle ki doğumdan ölüme kadar hayatın her safhasında sığır yetiştiriciliği Dinka klanlarını direk veya dolaylı olarak etkilemektedir. Dinkalar sığılların sahip olduğu renklere çeşitli anlamlar yüklemiştir. Sığırların ahlaki ve yaratıcı önemi, onların normal hayat içerisinde ne kadar önemli olduğunun da bir göstergesidir. Onlara göre bir insan sığırlar olmadan tam bir Dinka olamaz. Sığırlar öyle değerlidir ki erkeklerin onları elde etmek ve savunmak için gerekirse hayatını feda etmekten kaçınmaması gerektiğine inanılır. ${ }^{47}$ Dinka toplumunda her klanın ve ailenin kendi sığır sürüleri için otlak ve su sağlaması zorunludur. Yapılan ritüeller ve törenler bu çerçevede gerçekleşir. Dinkalar hayvanlarını otlatmak için verimli nehir kıyılarına gittikleri dönemlerde nehir için yıllık bir tören yapar. Genelde bu töreni Kic Dinka'nın bir sınıfı olan Din Faiwer'in bir üyesi icra eder. Törende çocuklar dahil herkes nehrin kıyısında durur. Nehir şefi, bir koyun veya keçi ile kutsal bir

46 Bedri, "More Notes on the Padang Dinka", 51-54.

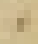

47 Kamwaria ve Katola, "The Role of African Traditional Religion, Culture and World-View in the Context of Post- War Healing among the Dinka Community of Southern Sudan", 50; Lienhardt, Divinity and Experience: The Religion of the Dinka, 10-27. 
inekten yapılmış tereyağı içeren bir su kabını (su kabağından yapılmış) tören için getirir. Törendeki insanlar koyunların boynuna boncuk, bilezik ve yüzük takar. Bu arada nehir şefi nehre dua eder. Tüm katılımcılar göğe doğru kollarını kaldırır. Bu arada çocuklar omuzlarda taşınır. Nehir Şefi, süslenmiş koyunu bir şekilde öldürür veya yok eder. Nehir Şefi, nehre tereyağı atar ve katılımcılar bellerine kadar suya girer. Bu ritüelden önce suya girmek tabu sayıllır. ${ }^{48}$

\section{Geçiş Dönemleri}

Bilindiği üzere insan hayatının doğumdan ölümüne kadar çeşitli safhaları vardır. Bu safhalardan doğum, evlilik ve ölüm geçiş safhaları olarak tanımlanmaktadır. İnsanın doğumu ile başlayan bu geçiş dönemlerinin inanış ve uygulamalarının tüm toplumlarda farklılık göstermesi olağandır.

Dinkalar arasında çocuk sahibi olma önemli bir olgudur. Çocukların ölümü hoş karşılanmaz. Dinkalar arasında aşağıda sözleri verilen şarkı da bu duruma işaret edilmektedir.

Büyükannem, Aluel, Col'un kızı

Tanrı'nın reddettiği bir zaferle geldi.

Çok sayıda çocuk doğuran harika bir hanımefendi

Ama çapaları mezarlarını kazarken bitirdiler

Babama bufalodan yalnız bir boğa bırakıyorum

Şimdi sığır sürülerimizin peşinde olacaktık

Baykuş bütün gece evimizde ağlar

Gecenin kötü kuşu bizi mahvetti

Kuş gece ağlayarak şöyle der:

"Şafak söktügünde, şafak söktüğünde

Ey Deng oğlu, şafak söktüğünde

Bir adam daha gömeceksin"

Gecenin kuşu babama kötü bir büyü yaptı.

Bizim toprağımız, bizim toprağımız

Biem'deki toprağımız, babam cesetlerle kaplı

Bir ayağın basması için yer kalmadı.

Yukarıda sözleri verilen şarkıda tanrının kaprisinden ve baykuşun lanetinin çocukların ölümüne sebep olduğundan bahsedilmektedir. ${ }^{49}$ Dinka toplumundaki bu inanış, uğursuz olarak kabul edilen hayvanların bazı toplumlarda da hala etkili olduğunun bir göstergesidir.

Her toplumda olduğu gibi Dinka toplumunda da bir çocuğun doğumu sevinçle karşılanır. Doğumla ilgili olarak öne çıkan en önemli husus çocuğa ad vermedir. Dinkalar da soy isim olmadığı

48 Molefi Kete Asante, "Dinka", Encyclopedia of African Religion, ed. Molefi Kete Asante- Ama Mazama (California: Sage Publication, 2009), 201-202; Bedri, "More Notes on the Padang Dinka", 53. 
için kişisel isimler çok önemli görülür. Çocuğa ad verilirken genelde toplumun soyunun olduğu ortak isimler, ataların isimleri, soyun totemlerinin isimleri öne çıkar. Dinka çocuklarının isimlerinin bir kısmı doğumdan çok önce bir kısmı da çocuk doğduktan belli bir süre sonra belirlenir. Örneğin; ilk ikiz erkek çocuklara Ngor ve Chan, kızlara Anger ve Achan isimleri; ikiz doğumlardan sonra erkek çocuklarına Bol, kız çocuklarına da Nyanbol veya Nyibol ile başlayan isimlerin verilmesi yaygındır. Ayrıca Dinkalar arasında renklerle ilgili isimlerin yanı sıra övmek amacı ile de isimlerin verildiği görülür. ${ }^{50}$

Dinka toplumunda evlilik soyun devamı açısından önemli görülür. Evlenecek erkek için evlilik bir tür sığır kaybı, aynı zamanda eşinin doğuracağı kız çocukları içinde ekonomik bir kazançtır. $O$ yüzden çocuk sahibi olmak önemlidir. Evlilik için ilk adım kız görmedir. Erkek, evleneceği kız ile bir süre arkadaşlık kurar. Bu süre içerisinde hem kızı tanır hem de kızla evlenmeye niyeti varsa ailesinin onayını alır. Ailenin onayı alındıktan sonra kızın ailesine haber gönderilir. Kızın ailesi tarafindan olumlu bir cevap geldikten sonra birkaç öküz, püsküllerle ve çanlarla süslenir. Evlenecek erkek ve ailesi süsledikleri hayvanlarla ritmik ve değişmeyen ses tonu ile şarkılar söyleyerek kızın evine gider. "Goor" adı verilen bir dans türü ile herkes dans eder. Kızın ailesi tarafından gelen misafirlere daha önce hazırlanmış yiyecek ve içecekler ikram edilir. Hazırlanmış olan bu ikramlar kızın ailesinin onurunun nişanesi olarak görülür. Getirilen sığırlar bağlanılır ve onlarla ilgilenilir. Sunulan ikramlar orada hazır bulunanlar tarafından yenilir. İki taraf arasındaki bu süreçte erkek ve kız aileleri ödenecek sığır sayısı hakkında konuşur. Konuşmaların olumlu geçmesi sonucunda iki ailenin gençleri artık nişanlı kabul edilir. O günden sonra çiftler için evlilik aşaması başlamış olur. İki ailenin de bu aşamadan sonra hak ve sorumlulukları başlar. Bu süreç içerisinde çiftler arasında cinsel ilişkiye izin verilmez. Bir süre sonra evlilik töreni yapılır. Evlilik töreni, iki aile içinde bir tür ticari faaliyet olarak görülür. Kızın akrabaları daha fazlasını elde etmek, erkek ailesi de az ödemek için çaba gösterir. Bu törenlerde eğlenceler düzenlenip yemekler yenilir. Evlilik ile ilgili son aşama "kızı verme" dir. Gelin, evden çıkmadan önce bazen belli bir süre geçebilir. Ama süre duruma göre değişkenlik gösterebilir. Son aşama olarak, gelin akrabalar eşliğinde damadın evine gider. Gelin, kocasının evinde yaklaşık iki hafta misafir gibidir. Daha sonra ev işleri başta olmak üzere her konuda eşine destek olur. ${ }^{51}$

Dinkalar klanlarında ölüm, bilinmeyenin korkusunun tezahür ettiği bir son olarak kabul edilir. Ölüm, genelde korku ve üzüntü uyandırır; çünkü hastalık gibi bulaşıcı olabileceğinden korkulur. Toplumda ölümler görüldüğünde çocuklar o yerden uzaklaştırılmaya çalışılır. Bir ölüm gerçekleştiğinde kadınlar ve erkekler ağlamaya başlar. Ölen kişinin mezar kazma işini genelde akrabaları üstlenir. Akrabalık bağı olmayanlar mecbur kalmadıkça mezara yaklaşmaz. Erkekler karınlarını bağlar ve mezarı kazar. Mezar kazılırken 3 feet $(0,91 \mathrm{~m})$ çapında ve 5 feet $(1,52 \mathrm{~m})$ derinliğinde yuvarlak bir delik şeklinde olmasına özen gösterilir. Bununla birlikte mezarın altında ise özel bir alan hazırlanır. Ölen kişi mezara yüzü güneye gelecek şekilde yatırılır. Mezara konulma işlemi başladığında kadınlar çığlıklarla ağlamaya başlar. Ölen kişi bir hastalıktan ölmüşs ise hastalığı esnasında kullandığı su kapları mezarda kırılır. Ölen kişi toprakla buluşturulduktan sonra ölen kişinin yakınları tehlikeli görülüp diğer insanlar tarafından onlara yaklaşılmaz. Bu durum tabu olarak görülür. Ölünün arkasından yas tutulur. Yas süresi duruma ve şartlara göre değişkenlik gösterebilir. Yas süresince süs eşyaları takılmaz. Yas süresi sonunda törenle temizlenilir ve normal

$\begin{array}{ll}50 & \text { Deng, } 38 . \\ 51 & \text { Deng, } 93-98 .\end{array}$


hayata dönülür. Dinka toplumunda ölüler ve yaşayanlar arasındaki ilişki “cuol” adı verilen bir ritüelle paradoksal olarak ayrılır. Ölen kişinin cinsiyetine göre üç veya dört gün sonra çiftlik evlerinden uzakta, gece yarısı bir tavuk veya koç kurban edilir. Kesilen bu kurban eti akrabalar tarafından yenilmez. İcra edilen bu ritüelle, adamı öldüren hastalığın yaşayanlar arasından uzaklaştırma fikri ön plandadır. ${ }^{52}$ Ölümle ilgili başka bir inanışta küçük bir çocuğun evlenmeden ölmesidir. Böyle bir durumda çocuğun akrabalarından biri, onun çocuk sahibi olabilmesi adına evlenebilir. Bu evlilikten doğacak çocuklar, ölenin çocuğun olduğu gibi biyolojik ebeveynlerinin de çocukları sayılır. ${ }^{53}$

\section{Sonuç}

Afrika kıtası üzerinde birçok etnik grubu barındırmaktadır. Bu etnik gruplardan bir tanesi de Güney Sudan'da yaşayan Dinkalardır. Yarı göçebe bir yaşam tarzı benimseyen bu toplum, uzun süre bölgedeki savaşlardan ve sömürgeci devletlerin baskılarından nasibini almıştır. Klanlar halinde yaşayan bu toplum son dönemlerde yanı başlarında yaşayan Nuer toplumu ile de sık sık sığır hırsızlıkları ve sığırları otlatma yeri konusunda çatışmalara maruz kalmıştır.

Bilindiği gibi günümüzde yaşayan birçok kabilenin din anlamında bir kurucusu ve kutsal bir kitabı yoktur. Bu çerçevede Dinkalar da bir kurucudan ve kutsal metinlerden bahsetmek olanaksızdır. Dinka dini denilince, sadece tanrıya değil aynı zamanda atalar ve tabiat güçlerine inanmak da kastedilmektedir. Geleneksel Dinka dininde yüce varlık Nhialik, gökte bulunan ve ulaşması zor olan bir tanrısal bir varlıktır. Bu tanrısal varlık daha aşağıda bulunan ruh ve tanrıları da yönetmektedir. Geleneksel Afrika Dinlerinin birçoğunda olduğu gibi Dinka toplumunda da tanrısal varlıkları memnun etme düşüncesi yaygındır. Bu yüzden bu insanüstü varlıklar için bazı törenler yapılıp, kurban kesme inanışı bulunmaktadır. Kurban geleneği ilk insandan itibaren dini bir gelenek olarak birçok dinde de kendini göstermiştir.

Dinka toplumunda geleneksel yapının oluşmasında mitolojinin ve sözlü geleneğin çok büyük bir etkisinin olduğu rahatlıkla söylenebilir. Nesilden nesile anlatılan bu şifahi gelenek toplumdaki birçok inanış ve uygulamaya da yön vermiştir. Bu geleneksel yapı içerisinde göze çarpan en önemli kavram yüz nişanı ritüelidir. Bu uygulama Dinka klanlarındaki erginlenme törenlerinin nihai bir sonucudur. Ergenlik çağına gelmiş erkek çocuklara yapılan bu tören, şiddet ve cesaretin zirveye ulaştı̆̆ bir ritüel olarak da görülmektedir.

Dinkalar da bölgedeki diğer Nilotik halklar gibi ölmüş atalarının birtakım güçlere sahip olduğuna inanmaktadır. Dolayısı ile atalarının ruhları onlar için bir şifacı veya onlara musallat olan bir ruh şeklinde görülmektedir. Onlar ile olan münasebetleri sonucunda onlar için çamurdan küçük mabedler inşa etmişlerdir. Bununla birlikte ata ruhları ile ilişskili olarak, Dinka savaşçılarının ruhlarının kirlendiği ve bu kirden arınmak için temizlenme ritüelleri yaptıkları belirtilmektedir. Bu ritüeller sonucunda toplum içerisinde daha rahat bir şekilde yaşadıklarına inanmaktadırlar.

\section{Kaynakça}

Adewale, S. A. “Afrika’nın Geleneksel Dininde Kurban”. Çeviren Ahmet Güç. Uludăg Üniversitesi İlahiyat Fakültesi Dergisi 7, sy 7 (1998): 587-600.

53 Asante, "Dinka", 202. 
Arslan, Hammet. “Afrika Topluluklarında Atalar Kültünün Önemi ve İşlevi”. Bartın Üniversitesi İslami İlimler Fakültesi Dergisi 3, sy 6 (2016): 7-27.

—. "Afrika Topluluklarında Tabiat Kültü ve Tabii Unsurlara Atfedilen Güçler”. Bartın Üniversitesi İslami İlimler Fakültesi Dergisi 4, sy 8 (2017): 2-16.

Asante, Molefi Kete. "Dinka". Encyclopedia of African Religion, editör Molefi Kete Asante ve Ama Mazama, 201-3. California: Sage Publication, 2009.

Bankole, Katherine Olukemi. "Creation”. Encyclopedia of African Religion, editör Molefi Kete Asante ve Ama Mazama, 184-86. California: Sage Publication, 2009.

Bedri, Ibrahim. "More Notes on the Padang Dinka". Sudan Notes and Records 29, sy 1 (1948): 40-57.

Burton, J. W. "Dinka". Worldmark Encyclopedia of Cultures and Daily Life, editör Timothy L. Gall ve Jeneen Hobby, 1:158-62. Printed in the United States of America: Gale-Cengage Learning, 2009.

Deng, Francis Mading. The Dinka of the Sudan. IIIinois: Waveland Press, 1972.

Evans, E.E., ve Pritchard. Nuer Religion. Oxford: Clarendon Press, 1956.

- The Nuer. Oxford: Clarendon Press, 1946.

https://www.aa.com.tr/tr/dunya/guney-sudanda-yetiskinligin-ve-gosterisin-ilk-sarti-yuznisani/976200\# (Erişim 15/05/2021), t.y.

Kamwaria, Alex, ve Michael Katola. "The Role of African Traditional Religion, Culture and World-View in the Context of Post- War Healing among the Dinka Community of Southern Sudan”. International Journal of Humanities and Social Science 2, sy 21 (2012): 49-55.

Kavas, Ahmet. "Sudan". Türkiye Diyanet Vakfi İslam Ansiklopedisi, 37:461-66. İstanbul: Türkiye Diyanet Vakfı Yayınları, 2009.

Lienhardt, Godfrey. Divinity and Experience: The Religion of the Dinka. Oxford: Clarendon Press, 1961.

Lynch, Patricia Ann. "Jok”. İçinde African Mythology A to Z, 53-54. New York: Fact on File, 2004.

Middleton, John. "Nuer and Dinka Religion". Encyclopedia of Religion, editör Lindsay Jones, 10:6743-45. Detroit: Macmillan Reference USA, 2005.

Nebel, Arthur. "Dinka-English, English-Dinka Dictionary”. Bologna: E.M.I, 1979.

Stokes, Jamie. "Dinka". Encyclopedia of the Peoples of Africa and Middle East, editör Anthony Gorman ve Andrew Newman, 173-76. New York: Infobase Publishing, 2009.

Thomas, Douglas, ve Temilola Alanamu, ed. African Religions: Beliefs and Pratices through History. Santa Barbara: ABC-CLIO, 2019. 